\title{
Rainfall thresholds derivation for warning pluvial flooding risk in urbanised areas
}

\author{
Angela Candela ${ }^{1, a}$ and Giuseppe Tito Aronica ${ }^{2}$ \\ ${ }^{1}$ DICAM, University of Palermo, 90128 Viale delle Scienze, Palermo, Italy \\ ${ }^{2}$ Dipartimento di Ingegneria, University of Messina, 98166 Contrada Di Dio, Messina, Italy
}

\begin{abstract}
Aim of this work is the development of an operational tool for pluvial flooding warning in an urban area based on off-line rainfall thresholds derived by coupling a rainfall-runoff modelling and a hydraulic routing. The critical conditions considered for issue flood warnings were not only based on the water stage, but also on the extension of the flooded area. Further, a risk assessment framework for quantifying the reliability of the rainfall thresholds has been included; rainfall thresholds used in pluvial flooding warning should be influenced by the uncertainties in the rainfall characteristics (i.e. rainfall duration, depth and storm pattern). This risk assessment framework incorporates the correlated multivariate Monte Carlo simulation method, an hydraulic model for the simulation of rainfall excess propagation over surface urban drainage structures, i.e. streets and pathways. Thresholds rainfall are defined using a number of inundation criteria, to analyze the change in the rainfall threshold due to various definitions of inundation. Starting from estimated water stages and flooded area from inundation simulation rainfall thresholds can be obtained according a specific inundation criterion, including, together, a critical water depth and a critical flooding area. Finally, the second phase concerns the imminence of a possible hydrological risk by comparing the time when cumulative rainfall and rainfall thresholds meet to each other. The developed procedure has been applied to the real case study of Mondello catchment in Palermo (Italy).
\end{abstract}

\section{Introduction}

Floods are natural phenomena which cannot be prevented; many studies show that the severity and frequency of floods have increased in recent years and underline the difficulty to separate the effects of natural climatic changes and human influences as land management practices, urbanisation, etc. [1-6]. As consequence, interest towards careful methodologies for the assessment of flood-prone areas has significantly increased.

Floods, generally, are divided into two main categories: general floods, which are caused by precipitation, occurring during a long period over a given river basin, and flash floods, that usually affect basins less than $1000 \mathrm{~km} 2$, with response times of a few hours or less. Moreover, Mediterranean ephemeral streams have specific features compared to other river systems. These basins are small and highly torrential and may generate flash-floods [7]. Runoff generation in semiarid zones is the result of many spatial and temporal complex processes related to hillslope and catchment scale. The complexity of the processes involved derives from great heterogeneity of rainfall inputs, surface and subsurface characteristics, and strong nonlinear dependency on antecedent wetness, which controls the infiltration capacity of the soil surface and the connectivity of surface and subsurface runoff pathways [8].

Moreover, the rapid transformation processes of urban areas induced, consequently, the increase of catchment imperviousness and the derived increase of surface runoff generated during rainfall events. The natural drainage network is, often, insufficient to convey such discharges and it is gradually substituted by artificial systems having the function to convey the runoff coming from urban areas towards the closest receiving water body. However, flooding events in urban areas occur quite frequently because of rain events of lower intensity than the design one, even in case of correct network dimensioning.

Large research efforts have been made on the flashflood analysis and modelling despite the lack of accurate measured rainfall and discharge data $[5,9,10]$. Usually, flash floods take place in steep mountain streams or in urban areas $[11,12]$. The lack of data on flash floods and in particular the lack of accurate discharge estimates, can often provide an obstacle to improvements in flood forecasting, warning, planning and emergency management.

Usually, flood warning systems are based on on-line hydrological and/or hydraulic models in order to provide forecasts of water stages or discharges at critical river sections [13-15]. This procedure is inappropriate for flash flood warning in urban areas or in catchments with a

\footnotetext{
a Corresponding author: angela.candela@unipa.it
} 
small area. Therefore, it would be helpful for the flash flood alter to be in accordance with the observed or forecasted rainfall if exceeding a critical value, namely, the rainfall threshold. Generally, rainfall thresholds identify precipitation critical values in the context of landslides and debris flow hazard forecasting [16, 17] and in the flood forecasting. A number of approaches have been proposed for the determination of the rainfall threshold for flood forecasting or warning [18-20, 13, 21, 22, 14, 23, 24, 15]. In Europe, the Integrated Project FLOODSite [25], among others aims at assessing the advantage for using the rainfall threshold approach as an alternative to the traditional ones in the case of flash floods.

In these cases, the change of rainfall in time may be more important than the total rainfall accumulation for flood forecasting. According to the approach proposed by $[19,15]$, in this study the rainfall threshold has been estimated in an urban area by coupling results of hydrodynamic model in terms of water stage and flooding area. Particularly, dependency of the antecedent soil moisture conditions has been neglected because urban areas are characterized by imperious surfaces.

Because incomplete processes understanding and uncertainties associated with the current prediction, flood prediction methods and analysis are, still, uncertain. Many studies have shown that sources of error propagate through the model and affect its output [26-32]. Main uncertainty sources have been identified: observation uncertainty (rainfall, river discharge, current velocities...), flood frequency analysis, choice of hydraulic model (0-, 1-, 2-dimensional model), model parameterisation (i.e. hydraulic roughness), high resolution and high accuracy topographic data sets, representation of linear elements (i.e. road embankments).

\section{Methodology}

This study proposes a methodology to point out in urban areas rainfall thresholds used in flash flood warning which should be influenced by the uncertainties in the rainfall characteristics, including rainfall duration, depth and storm pattern. Particularly, the methodology here developed has a modular structure consisting of different modules: synthetic hyetographs definition to gain the hydrological input to the hydraulic model; transformation of flood discharge to inundated area through a two-dimensional hydraulic model the FLURB2D model [33] and, finally, quantification of threshold rainfall associated with specific inundation criteria.

\subsection{Synthetic hyetographs derivation}

Rainfall depth and duration can be directly calculated from observations recorded at the raingauges in the catchment. In order to define the temporal patterns of rainfall for each event, we used here the idea of mass curves [34- 37]. The variability of precipitation within a rainy period is represented by a dimensionless hyetograph $H(d)$ :

$$
H(d)=\frac{1}{I \cdot D} \int_{0}^{t} h(t) d t
$$

that identifies the fraction of rainfall accumulated over the time interval $[0, d] ; t(0 \leq t \leq D)$ is a fraction of the total duration $D$ of the considered event and $d=t / D(0$ $\leq d \leq 1)$ is the correspondent dimensionless duration, $h(t)$ is the rainfall depth at time $t(0 \leq h \leq V), V=I \cdot D$ is the total storm volume and $D$ the storm duration for the event.

\subsection{Flood propagation}

FLURB-2D is a two-dimensional inertial model based on the Saint Venant equations originally developed for simulating the overland flow propagation on alluvial plains with uneven topography and applied to urban areas $[26,33]$. Only the convective terms are neglected in order to eliminate the related numerical instabilities and to maintain the efficiency of the hyperbolic scheme in dealing with flow fields with small water depths:

$$
\begin{array}{r}
\frac{\partial H}{\partial t}+\frac{\partial p}{\partial x}+\frac{\partial q}{\partial y}=0 \\
\frac{\partial p}{\partial t}+g h \frac{\partial H}{\partial x}+g h J_{x}=0 \\
\frac{\partial q}{\partial t}+g h \frac{\partial H}{\partial y}+g h J_{y}=0
\end{array}
$$

where $H(t, x, y)$ is the water surface elevation, $p(t, x, y)$ and $q(t, x, y)$ are the $x$ and $y$ components of the unit discharge (per unit width), $h$ is the water depth, $J_{x}$ and $J_{y}$ are the hydraulic resistances in the $x$ and $y$ directions. If Manning's formula is adopted, these last two terms can be expressed as:

$$
J_{x}=\frac{n^{2} p \sqrt{p^{2}+q^{2}}}{h^{10 / 3}} ; \quad J_{y}=\frac{n^{2} q \sqrt{p^{2}+q^{2}}}{h^{10 / 3}}
$$

where $n$ is Manning's roughness factor.

FLURB-2D model equations are solved using a Galerkin finite element technique with triangular elements [26]. The water-surface elevation is assumed to be continuous and piecewise linear inside each element, where the unit discharges along the $\mathrm{x}$ and $\mathrm{y}$ directions are assumed to be constant. The finite element approach avoids a simplified description [38-40] of the hydraulic behaviour of flooded areas because triangular elements are able to reproduce the detailed complex topography of the built-up areas, i.e. blocks, streets, etc. exactly as they appear within the floodable area. Particularly, blocks and other obstacles are treated as internal islands or internal boundaries within the triangular mesh covering the entire flow domain. For further details about the hydrodynamic model please refers to $[26,33]$. This "physically based" description of the geometric characteristics of the 
calculation domain allows considering, as inflow hydrographs, distributed rainfall hyetographs spatially varied over the domain.

\subsection{Threshold rainfall definition}

A flood warning status can be easily recognised in a fluvial cross-section based on the estimated water stage by the rating curve or the hydraulic routing with the calculated runoff. However, in a urban basin, flood inundation is mostly due to the overland flow attributed to the overtopping runoff or heavy rain, and is defined as "critical inundation" according to various inundation criteria, including the critical water depth and critical flooding area.

In this study thresholds rainfall are defined using the approach proposed by [15]; particularly, the flood inundation is defined when maximum water level and corresponding flooding area exceed critical values to find out the corresponding rainfall amount for the rainfall duration.

Starting from estimated water stages and flooding area from inundation simulation, carried out by the FLURB2D hydrodynamic model, rainfall thresholds can be obtained according a specific inundation criterion, including, together, a critical water depth and a critical flooding area [15]. In detail, for each rainstorm event, the first time step when the maximum of simulated water stages and the corresponding flooding area exceed specific inundation criteria. This time step, $t^{*}$, is named "time-to-inundation" and it differs for each rainfall event. Then, the corresponding rainfall threshold $\mathrm{R}_{\mathrm{i}}^{\mathrm{t}^{*}}$, for the $i$ event and for a duration $t$, can be calculated using:

$$
R_{i}^{t^{*}}=\sum_{t=0}^{t=t^{*}} R_{t}
$$

when $R_{t}$ is the rain at the time step $t^{*}$

\section{Case study}

To demonstrate the applicability of the proposed methodology for the rainfall threshold assessment, this study selected a urban basin as study area, Mondello catchment (Palermo) located in Sicily, Italy (figure 1). It is approximately $25 \mathrm{~km}^{2}$; until the beginning of the last century, this area was a semi-rural zone, covered by green surfaces and small fishing villages. During the past century, it has been progressively transformed into a tourist area, coupled with strong urban expansion; this fast urbanisation has not been coupled with adequate drainage systems aimed to collect stormwater. As consequence, during rainfall events, the runoff volumes mainly propagate along the roads. Due to capacity of the drainage system being highly related to change in rainfall $[41,42]$, the rainfall threshold plays an important role in the flash flood warning in this area. Moreover, the tourist relevance of the area and the great urbanisation, are incompatible with the adoption of centralised mitigation measures. The effective contributing urban area is approximately $25 \mathrm{~km}^{2}$ and its drainage systems (mainly superficial) concur into a strongly urbanised area near to the sea where the greatest flooding and the greatest damage take place. A portion of the semi-rural catchments surrounding the urbanised area does not contribute to the runoff generation due to the catchment topography; some impervious areas retain the runoff volumes generating local flooding; other impervious areas are connected to pervious areas where the runoff volumes are infiltrated; some roads are actually equipped with underground infiltration structures.

A covered drainage channel (the so-called Ferro di Cavallo (Horseshoe) (red line in figure 1) delimits the area considered in this study. The channel was transformed into an underground sewer at the beginning of the twentieth century collecting both stormwater and wastewater from the urban area. Now the channel is disconnected by wastewater connections and it mainly drains stormwater [42].

The area delimited by the Ferro di Cavallo is characterised by an underground looped drainage network; in order to protect Mondello bay environment, drainage system outflows are not free but they are connected to two pump stations (each with a maximum flow rate equal to $0.5 \mathrm{~m}^{3} / \mathrm{s}$ ). During winter, the pumped volumes are discharged to the sea out of the bay, while, during summer, tourist activities do not allow for discharging stormwater near the cost and the water volumes are disposed of to a neighboring wastewater treatment plant. As stated above, the drainage system is often surcharged, also during low return period rainfalls, and local floodings occur in many zones. No rainfall measurements are available in this area.

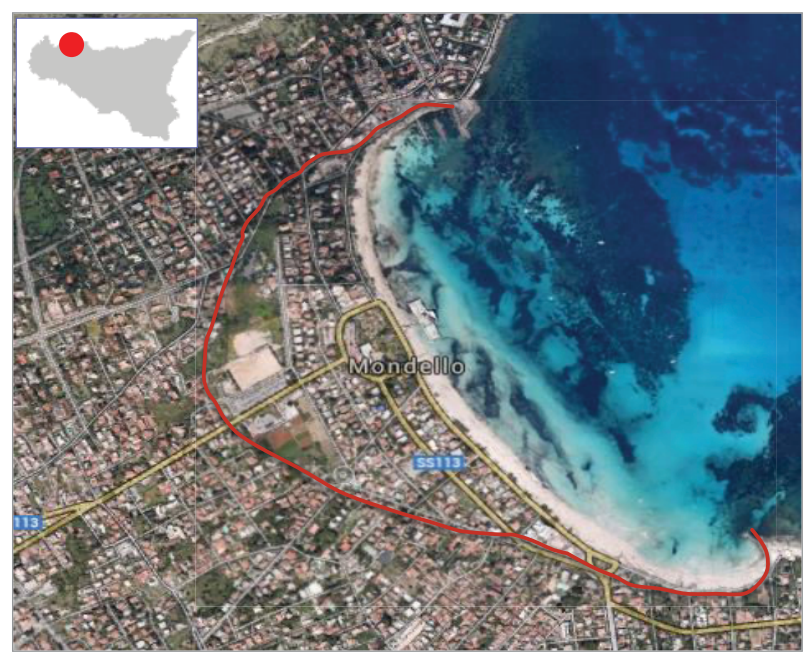

Figure 1. Mondello catchment and study area (red line).

\section{Results}

Independent rainfall events were derived starting from rainfall data recorded at the raingauge Uditore, located in Palermo city, around $10 \mathrm{~km}$ from the study area and managed by a Regional Agency (SIAS) from 2000. Starting from rainfall data recorded from August 2001 to September 2014 on 10 minutes basis, 1051 significant rainfall events have been extracted. 
Particularly, two events were considered independent if they were separated by a dry period of at least $3 \mathrm{~h}$. Information regarding rainfall events are summarized in Table 1. Rainfall events selected show a large range of volume (from $1 \mathrm{~mm}$ to $184.4 \mathrm{~mm}$ ) associated with the maximum intensity on 10-min basis (from $1.2 \mathrm{~mm} / \mathrm{h}$ to $148.8 \mathrm{~mm} / \mathrm{h}$ ), respectively. In addition, the durations of these events range from 30 to 2630 minutes.

\begin{tabular}{|c|c|c|c|c|}
\hline & $\begin{array}{c}\text { Average } \\
\text { max } \\
\text { intensity } \\
(\mathrm{mm} / \mathrm{h})\end{array}$ & $\begin{array}{c}10-\mathrm{min} \\
\mathrm{max} \\
\text { intensity } \\
(\mathrm{mm} / \mathrm{h})\end{array}$ & $\begin{array}{c}\text { Event } \\
\text { rainfall } \\
\text { volume } \\
(\mathrm{mm})\end{array}$ & $\begin{array}{c}\text { Event } \\
\text { rainfall } \\
\text { duration } \\
(\mathrm{min})\end{array}$ \\
\hline Max & 45.60 & 148.8 & 184.4 & 2640.0 \\
\hline Min & 0.19 & 1.2 & 1.0 & 40.0 \\
\hline Mean & 2.03 & 10.35 & 9.18 & 347.93 \\
\hline $\begin{array}{c}\text { Standard } \\
\text { deviation }\end{array}$ & 2.74 & 13.20 & 12.47 & 326.63 \\
\hline
\end{tabular}

Table 1. Information and statistics of the rainfall data for 1051 events registered from August 2001 to September 2014.

For the hydraulic simulations, 200 synthetic hyetographs have been generated using the Shuffle method constrained to the $10 \%$ and $90 \%$ percentiles of the historical events (fig. 2).

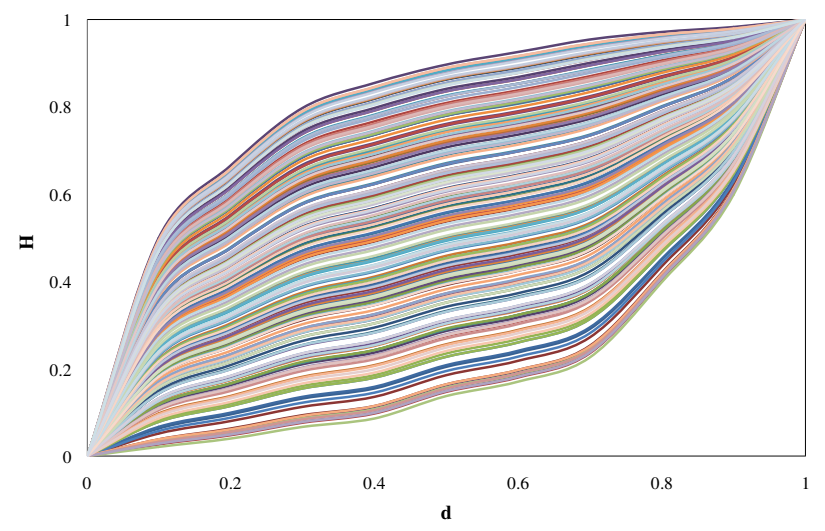

Figure 2. Dimensionless synthetic hyetographs used for the simulations

200 hydraulic simulations have been carried out by using as input to the 2-D model the 200 synthetic hyetographs derived above. A single value of Manning coefficient was fixed at $0.02 \mathrm{~s} / \mathrm{m}^{1 / 3}$ for the entire domain, chosen to account for the blockage effects due to the presence of debris, wood, stones, etc. [33, 43].

Hence, the rainfall threshold is determined based on the water stage and flooding area reaching their critical values. According to Section 2.2, a finite elements mesh of the study area is required. The derivation of the mesh was based upon the morphology of the study area in order to cover the whole surface drainage network. Buildings and other obstacles are considered as islands in the mesh. The total meshed area is about $0.31 \mathrm{~km}^{2}$, discretized as 22932 triangular elements. The geometric features (x,y,z coordinates) of 13208 nodes have been derived from a Digital Elevation Map (DEM) with $2 \mathrm{~m}$ resolution obtained from an IDW interpolation operated on the digital vector map $(1: 1000)$ containing information at variable resolution (contour lines plus a number of measured local elevations mainly located along the streets). In figs. 3 and $4 \mathrm{DEM}$ and the finite elements mesh for the study area are reported.

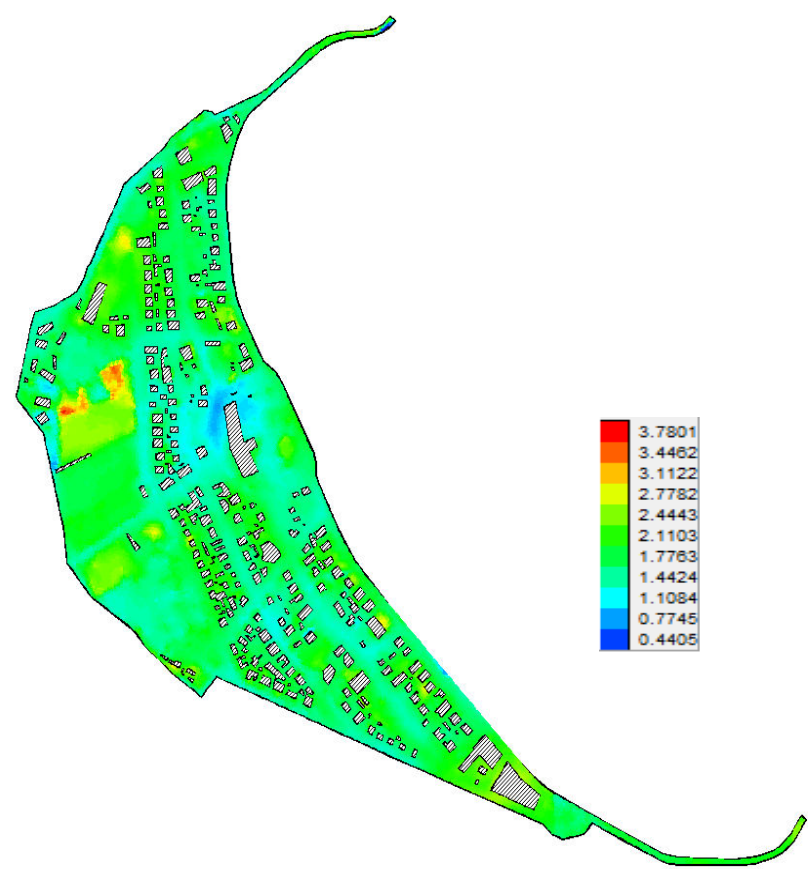

Figure 3. DEM (2m resolution) of the study area (elevation in meters above sea level)

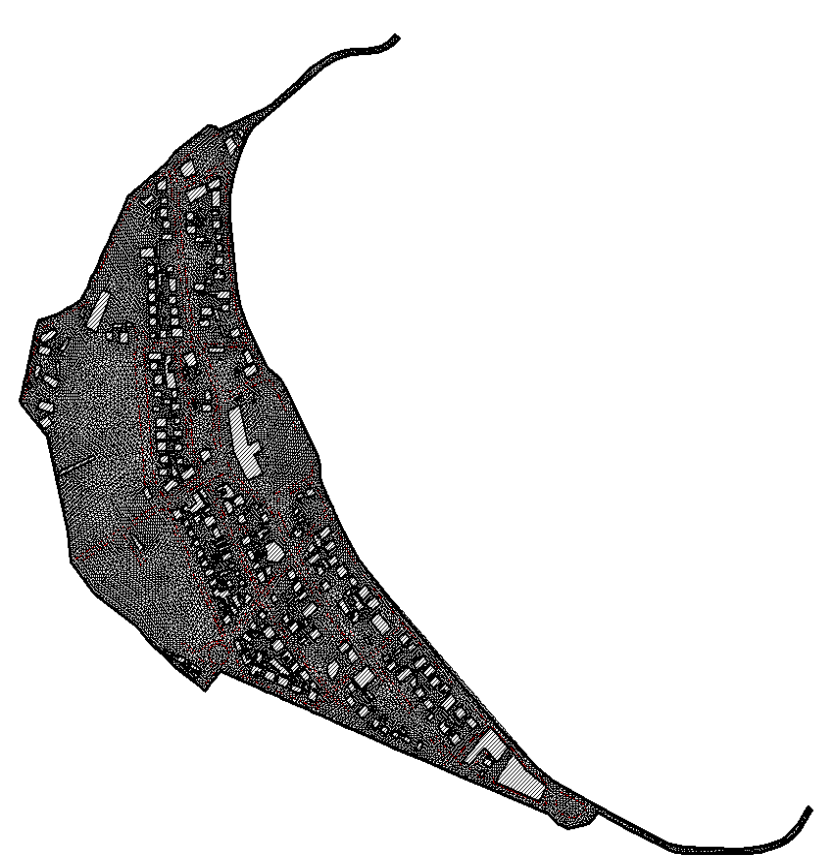

Figure 4. Finite elements mesh of the study area

Eventually, using the FLURB-2D model with 200 generated rainfall hyetographs, 200 simulations of flooding cases in the Mondello catchment are obtained. Figure 5 shows an example of the flooding simulation.

In accordance with [15] designed inundation criterion include, together, a critical water depth of $0.3 \mathrm{~m}$ and a critical flooding area of $5 \%$ of the total area. According to section 2.3, for each rainstorm event, the time to 
inundation has been evaluated and the rainfall threshold for various durations with simulated hyetographs has been calculated using equation (5) under the inundation criteria.

Figure 6 shows accumulated volume of rain versus corresponding times to inundation and rainfall threshold for the study area. Antecedent soil moisture conditions have been neglected because in urban areas soils can be considered impervious.

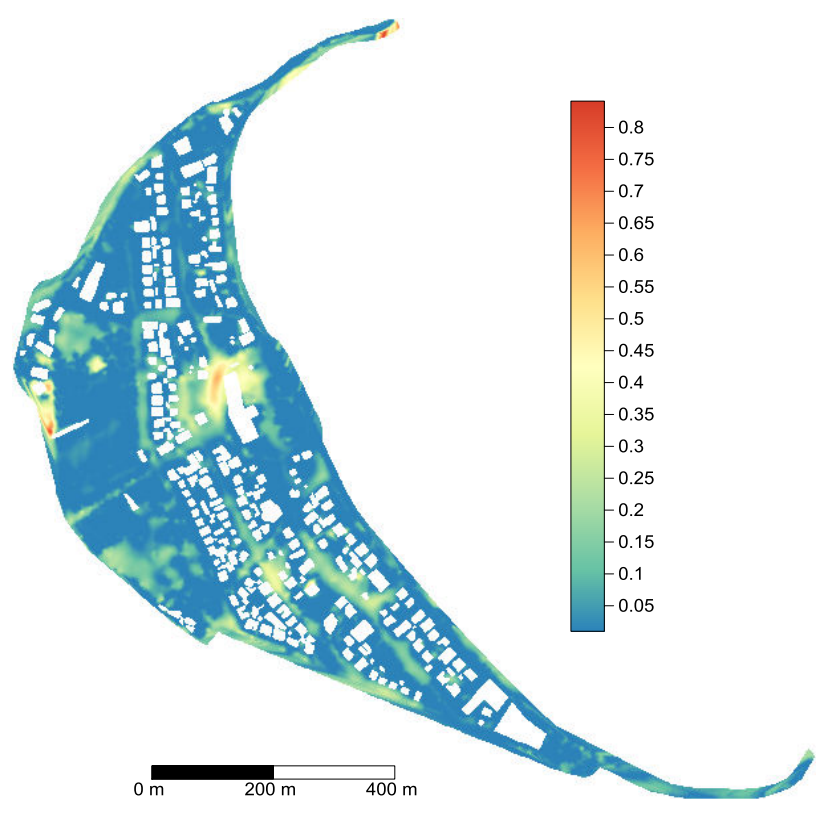

Figure 5. Example of single hydraulic simulations for given synthetic hyetographs and fixed rainfall duration and volume

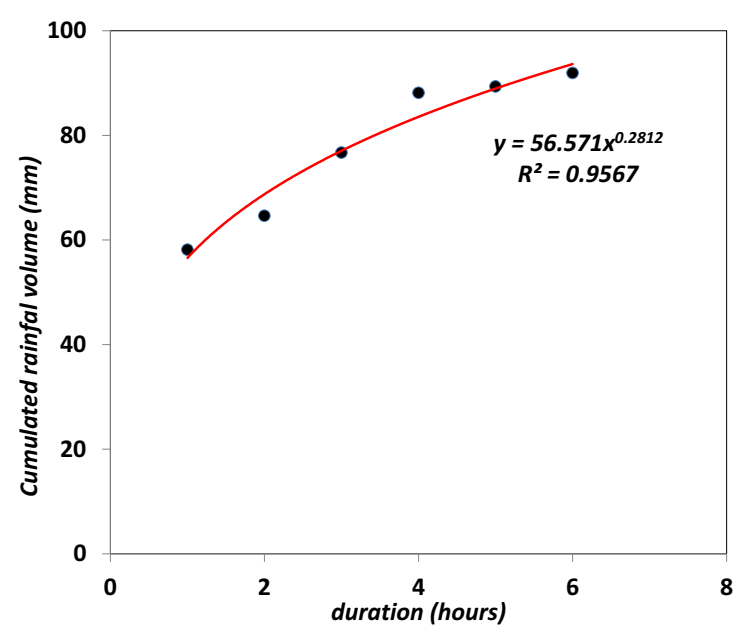

Figure 6. Rainfall threshold for given inundation criteria

\section{Conclusions}

Issuing warning information to the public when rainfall exceeds given threshold is a simple and widely used method for flood prevention

In this study, an advanced methodology is proposed to include the diversity of rainfall threshold for urban flooding;

Inundation criteria has been considered instead of the usual flooding flow

\section{References}

1. Blöschl G. and Montanari A. (2010). Climate change impacts-throwing the dice? Hydrological Processes, 24, 374-381

2. Centre for Research on the Epidemiology of Disasters (CRED) (2004). EM-DAT The International Disaster Database. Univ. Chatolique de Louvain, Brussels. http://www.emdat.be/database

3. Di Baldassarre G., Montanari A., Lius H., Koutsoyiannis D., Brandimante L., and G. Blöschl (2010). Flood Facilities in Africa: from diagnosis to mitigation. Geophysics Reserch Letter, 37, L22402, doi:10.1029/2010GL045467.

4. Kleinen T. and G. Petschel-Held (2007). Integrated assessment of changes in flooding probabilities due to climate changes. Climate Change, 81, 283-312.

5. Marchi L., Borga M., Preciso E., and E. Gaume (2010). Characterisation of selected estreme flash floods in Europe and implications for flood risk management. Journal of Hydrology, 394, 118-133.

6. OECD (2012). OECD Environmental Outlook to 2050: The Consequences of Inaction. Paris: OECD.

7. Camarasa-Belmonte A.M., and J.S. Soriano-Garcia (2012). Flood risk assessment and mapping in periurban Mediterranean environments using hydrogeomorphology. Application to ephemeral streams in the Valencia region (eastern Spain). Landscape and Urban Planning, 104(2), 189-200

8. Candela A., Noto V.L., and G.T. Aronica (2005). Influence of surface roughness in hydrological response of semiarid catchments. Journal of Hydrology, 313, 119-131

9. Gaume E., and M. Borga (2008). Post-flood field investigations in upland catchments after major flash floods: proposal of a methodology and illustrations. Flood Risk Management, 1, 175-189

10. Lumbroso D. and E. Gaume (2012). Reducing the uncertainty in indirect estimates of extreme flash flood discharges. Journal of Hydrology, 414-415, 1630

11. Ravazzani G., Mancini M. and C. Meroni (2009). Design hydrograph and routing scheme for flood mapping in a dense urban area. Urban Water Journal, 6 (3), 221-231

12. Melo N., Santos B.F. and L. Jorge (2015). A prototype tool for dynamic pluvial-flood emergency planning. Urban Water Journal, 12(1), 79-88

13. Martina M.L., Todini E. and A. Libralon (2006). A Bayesian decision approach to rainfall thresholds based flood warning. Hydrologic Earth System Sciences, 10, 413-426

14. Diakakis M. (2012). Rainfall threshold for flood triggering. The case of Marathonasin Greece. Natural Hazards, 60(3), 789-800

15. Wu S.J., Hs C.T., Lien H.C. and C.H. Chang (2015). Modeling the effect of uncertainties in rainfall characteristics on flash flood warning based on rainfall thresholds. Natural Hazards, 75, 1677-1711

16. Neary D.G. and L. W. Swift (1987). Rainfall thresholds for triggering a debris flow avalanching 
event in the southern Appalachian Mountains, Rewiews in Engineering Geology, 7, 81-95

17. Crosta G.B. and P. Frattini (2000). Rainfall thresholds for triggering soil slips and debris flow. Proceeding of 2nd plinius conference on mediterranean storms, Siena, Italy, 16-18

18. Capenter T.M., Spefslage J.A., Georgakakos K.P., Sweeney T. and D.L. Fread (1999). National threshold runoff estimation utilizing GIS in support of operational flash flood warning systems. Journal of Hydrology, 224, 21-44

19. Amadio P., Mancini M., Menduni G., Rabuffetti D. and G. Ravazzani (2003). A real time flood forecasting system based on rainfall thresholds working on the Arno watershed: Definition and reliability analysis. In: Proceedings of the 5th EGS Plinius Conference, Corsica, France

20. Georgakakos K.P. (2006) Analytical results for operational flash flood guidance, Journal of Hydrology, 317, 81-103, 2006

21. Norbiato D., Borga M., Esposti S.D., Gaume E. and S. Anquetin (2008) Flash flood warning based on rainfall thresholds and soil moisture conditions: an assessment for gauged and ungauged basins. Journal of Hydrology, 362, 274-290

22. Montesarchio V., Lombardo F. and F. Napolitano, (2009) Rainfall thresholds and flood warning: an operative case study. Natural Hazards and Earth System Sciences, 9, 135-144.

23. Golian S., Saghafian B., and R. Maknoon (2010) Derivation of probabilistic thresholds of spatially distributed rainfall for flood forecasting. Water Resoures Management, 24(13),3547-3559

24. Golian S., Saghafian B., Elmi M. and R. Maknoon (2011). Probabilistic rainfall thresholds for flood forecasting: evaluating different methodologies for modeling rainfall spatial dependence. Hydrological Processes, 25(13),2046-2055. doi:10.1002/hyp.7956

25. Samuels P. and B. Gouldby (2009). Language of risk. Project definitions, 2nd ed. Report T32-04-01. http://www.floodsite.net.

26. Aronica G.T., Tucciarelli T. and C. Nasello (1998). 2D multilevel model for flood Wave propagation in flood-affected areas. Journal of Water Resources, Planning and Management, 124 (4), 210-217

27. Aronica G.T., Bates P.D. and M.S. Horritt (2002). Assessing the uncertainty in distributed model predictions using observed binary pattern information within GLUE. Hydrological Processes, 16, 2001-2016

28. Horritt M. S., and P. D. Bates (2002). Evaluation of 1-D and 2-D models for predicting river flood inundation. Journal of Hydrology, 268, 87-99.

29. Di Baldassarre G., Castellarin A., Montanari A. and A. Brath (2009). Probability weighted hazard maps for comparing different flood risk management strategies: a case study. Natural Hazards, doi:10.1007/s11069-009-9355-6.

30. Neal J. C., Villanueva I., Wright N., Willis T., Fewtrell T. and P. D. Bates (2012). How much physical complexity is needed to model flood inundation? Hydrological Processes, 26, 2264-2282.
31. Pappenberger F., Beven K., Frodsham K., Romanowicz R. and P. Matgen (2007). Grasping the unavoidable subjectivity in calibration of flood inundation models: A vulnerability weighted approach, Journal of Hydrology, 333, 275-287.

32. Romanowicz, R. and K. Beven (2003). Estimation of flood inundation probabilities as conditioned on event inundation maps. Water Resources Research, 39(3), 1073-1085.

33. Aronica G.T. and L.G. Lanza. (2005). Drainage efficiency in the urban environment. Hydrological Processes, 19(5), 1105-1119.

34. Huff F. A. (1967). Time distribution of rainfall in heavy storms, Water Resources Research, 3, 10071019.

35. Garcia-Guzman A. and E. Aranda-Oliver (1993). A stochastic model of dimensionless hyetograph, Water Resources Research, 29, 2363-2370.

36. Wu S.J., Tung Y.K. and J.C. Yang (2006). Stochastic generation of hourly rainstorm events. Stochastic Environmental Research on Risk Assessment, 21, 195-212.

37. Candela A. Brigandì G. and G.T. Aronica (2014). Estimation of synthetic flood design hydrographs using a distributed rainfall-runoff model coupled with a copula-based single storm rainfall generator, Natural Hazards and Earth System Sciences, 14, 1819-1833, doi:10.5194/nhess-14-1819-2014.

38. Chen A.S., Evans B., Djordjevi, S. and D.A. Savic, (2012). A coarse-grid approach to representing building blockage effects in 2D urban flood modelling. Journal of Hydrology, 426-427, 1-16

39. Néelz S. and G. Pender (2007). Sub-grid scale parameterisation of 2D hydrodynamic models of inundation in the urban area. ActaGeophysica, 55 (1), 65-72

40. Yu D. and S.N. Lane (2006). Urban fluvial flood modelling using a two-dimensional diffusion-wave treatment, part 1: mesh resolution effects. Hydrological Processes, 20(7), 1541-1565

41. Zhou Q., Mikkelsen P.S., Halsnæs K., and K. Arnbjerg-Nielsen (2012). Frameworkfor economic pluvial flood risk assessment considering climate change effects and adaptation benefits. Journal of Hydrology, 414-415, 539-549

42. Freni G. and E. Oliveri (2005). Mitigation of urban flooding: A simplified approach for distributed stormwater management practices selection and planning, Urban Water Journal, 2(4), 215-226.

43. Aronica G. T., Candela A., Fabio p. and M. Santoro (2012). Estimation of flood inundation probabilities using global hazard indexes based on hydrodynamic variables, Physics and Chemistry of the Earth, 4244, 119-129 